\title{
Molecular classification of infiltrating ductal carcinomas in Western Algeria
}

Hayette Sénia Bensaber ${ }^{1,2}$, Ouafa Badre², Azziz Mohamed Bensnouci³, Samia Khalifa ${ }^{4}$, Fatima Zohra El Kebir ${ }^{1}$, Tewfik Sahraoui ${ }^{1}$

\begin{abstract}
${ }^{1}$ Laboratory of Developmental Biology and Differentiation (LBDD), Ahmed ben Bella Oran 1 University, Oran, Algeria

${ }^{2}$ Faculty of Natural and Life Sciences, Department of Applied Molecular Genetics (GMA), Mohamed Boudiaf Oran University of Science and Technology (USTOMB), Oran, Algeria

${ }^{3}$ Pathology Laboratory of the Oran Regional University Military Hospital (HMRUO), Oran, Algeria

${ }^{4}$ Laboratory of Anatomy and Pathological Cytology, University Hospital Establishment, Oran, Algeria
\end{abstract}

Submitted: 18 March 2021

Accepted: 2 June 2021

Arch Med Sci Aging 2021; 4: e27-e32

DOI: https://doi.org/10.5114/amsa.2021.107806

Copyright @ 2021 Termedia \& Banach

\section{Abstract}

Introduction: Breast carcinoma is a heterogeneous pathology. These subtypes are known to vary in terms of risk factors, natural histories and responses to therapies. The prognostic classification based on gene expression and genomic profiling was implemented to refine therapeutic indications and improve patient survival. Our goal is to classify infiltrating channel carcinomas according to their molecular profiles and analyze the different clinicopathological variables of these molecular groups.

Material and methods: We conducted a 24-month retrospective study involving 50 patients recruited from the Oran University Hospital and the Oran Regional Military Hospital. Tumors were analyzed histologically and classified after an immunohistochemical study in groups: luminal A, luminal B, Her2+ and basal-like.

Results: Our study showed the predominance of molecular subtype luminal B (36\%) of which $55.56 \%$ of these tumors were of Scarff-Bloom-Richardson (SBR) grade II and $44 \%$ were of grade III. $55.56 \%$ were T2 size followed by T1 size with a percentage of about $33.33 \%$. Axillary ganglionic metastases were found in $88.89 \%$ of cases, followed by luminal A (32\%) with $62.5 \%$ grade III, and $37.5 \%$ grade SBR II. Thus $37.5 \%$ of these tumors were of stage T2 and T4. Axillary ganglionic metastases were present in $87.5 \%$. The HER2 type (20\%) with $60 \%$ SBR II grade and $40 \%$ grade III. All basal-like tumors represented the highest SBR grade III with a percentage of $100 \%$.

Conclusions: Molecular classification is crucial in the direction of treatment.

Key words: breast cancer, molecular subtypes, hormonal receptors (RH), HER2 status, proliferation index (Ki67).

\section{Introduction}

Breast cancer is the most common cancer in women. This pathology represents a real major public health problem [1]. According to the latest estimates in 2018 , the incidence has increased by more than $24.2 \%$ and mortality by $15 \%$ worldwide.

\author{
Corresponding author: \\ Hayette Sénia Bensaber \\ Laboratory of \\ Developmental Biology \\ and Differentiation (LBDD) \\ Ahmed ben Bella \\ Oran 1 University \\ Coopérative dar el \\ amel cité hachemi ghazeli \\ Oran, Algérie \\ Phone: +213770542614 \\ E-mail: bensaber.hayette@ \\ yahoo.fr
}


In Algeria, the rate of breast cancer is around 180,537 new cases per year, the percentage of which is $16.3 \%$. The current therapeutic strategy is based on clinical and anatomopathological classification studies (TNM and PTNM), which make it possible to assess the locoregional extension at the time of surgery, but also to establish the stage of cancer progression [2].

The TNM classification includes clinicopathological parameters such as: tumor size $(T)$, presence of lymph nodes $(\mathrm{N})$ and presence of metastases (M) [3].

The predominant function of histological classification is to subdivide tumors according to their pathological nature into non-infiltrating tumors (ductal carcinoma in situ and lobular carcinoma in situ) and into infiltrating tumors with metastatic potential [4].

Given the increasing availability of new anti-tumor molecules, it is crucial to improve the prognostic classification of breast cancer to refine the therapeutic indications and improve patient survival, through a more detailed and objective molecular characterization of the pathology [4].

The objective of our present study is to classify the infiltrating mammary carcinomas collected at the University Hospital of Oran "November 1, 1954" and at the Regional Military University Hospital of Oran (HMRUO) according to their molecular profiles, then analyze the different clinicopathological variables of these tumors.

\section{Material and methods}

\section{Population of study}

This is a retrospective study spread over 24 months, comprising 50 patients aged between 35 and 83 years from West Algeria collected from the university hospital establishment of Oran (EHUO) "November 1, 1954" and the Regional Military University Hospital of Oran (HMRUO) for diagnosis, monitoring and management.

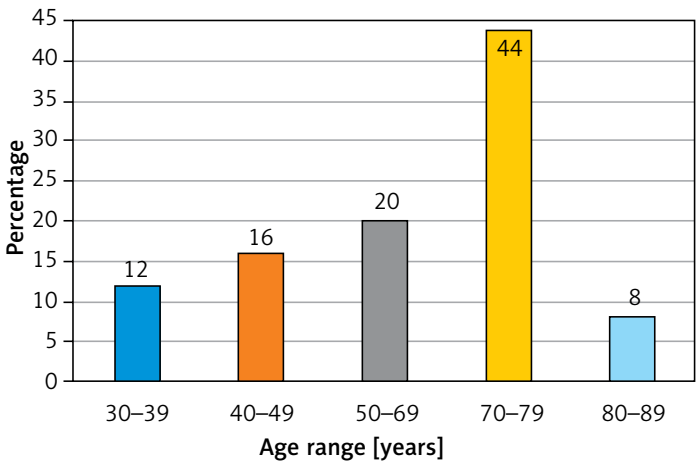

Figure 1. Graphical distribution of patients according to age

\section{Methods}

The study was performed on biopsies and surgical specimens fixed in $10 \%$ formalin and embedded in paraffin. Our tumor samples were analyzed histologically and classified after an immunohistochemical study into groups: luminal A, luminal B, HER2 and basal-like.

The analysis concerned the following parameters: age, TNM tumor stage [3], Scarff-Bloom- Richardson (SBR) [5] histological grade, lymph node involvement, distant metastases, receptor status, hormones, the HER2 receptor (human epidermal growth factor) and the proliferation index Ki67.

The immunohistochemistry technique was performed with the Leica BOND-MAX device in fully automated mode and the antibodies used were: RE (clone BV3; Ref: Mob 124 Mob195); RP (BV7 clone; Ref: RMABO28); HER2 (c-erbB2) (BV5 clone; Ref: RMABO26); Ki67 (SP6 clone; Ref: RMABOB04).

\section{Statistical analysis}

Statistical analysis and data processing were performed with the software IBM SPSS version 20. The $\chi^{2}$ are test were used to determine the correlations. A $p$-value $<0.05$ was considered statistically significant. The data were reported as clinical stage of tumor, lymph nodes status, metastatic status, SBR grade, ER/PR status, and HER2 expression.

In ethics and professional conduct, all of our patients responded to the medical questionnaire with informed consent.

\section{Results}

The careful combination of histological and immunohistochemical parameters results in better classification compared to their individual use, thereby confirming that molecular mechanisms and clinical outcomes are linked to ensure a better understanding of the mechanisms of breast cancer.

\section{Descriptive study of the sample}

Our population included patients between 35 and 83 years old from western Algeria. According to our study, patients aged less than 69 years present the lowest frequencies, with respectively $12 \%, 16 \%$ and $20 \%$. These rates increased from the fourth age group 70-79 years with a frequency of $44 \%$, but the age group $80-89$ years noted a low frequency of $8 \%$ (Figure 1 ).

Grade III SBR (Scarff-Bloom-Richardson) tumors in our study population rank first, with $56 \%$ of cases, followed by grade II tumors at $44 \%$.

Tumor size was an important prognostic factor. The latter was evaluated in the 50 patients that we followed and who presented tumors in stage 
T2, the frequency of which was $48 \%$. Concerning size, $\mathrm{T} 1 \mathrm{had}$ a percentage of $28 \%$, followed by size T4 with $16 \%$, followed by size T3, which was the least frequent, with a percentage of $8 \%$. Out of 50 lymph node dissections examined, $80 \%$ of the lymph nodes were invaded by the tumor process, of which we found 24 (48\%) of them presented with stage N1, 12 (24\%) patients presented with stage N2, 4 other patients presented with stage $\mathrm{N} 3$ with percentages of $8 \%$ and $20 \%$ of the patients were carriers of healthy nodes classified NO (Table I).

The degree of positivity of hormone receptors was proportional to cell differentiation, which measured the receptivity of the tumor to hormone therapy. In our series, $68 \%$ of patients expressed estrogen receptors, and also $56 \%$ of cases were positive for progesterone receptors.

There was overexpression of the HER2 protein, the percentage of which was $56 \%$ versus $44 \%$ of patients with a negative HER2 profile (Table I).

For all of our patients, we found $44 \%$ of cases with a Ki67 status less than 14 (ki67 low), and $56 \%$ of cases with a ki67 status greater than 14 (ki67 high) (Table I).

\section{Distribution of invasive ductal carcinomas according to molecular classification}

We were able to identify for each tumor the molecular class according to its immunohistochemical profile (study of hormone receptors $(\mathrm{RH})$, membrane receptor (HER2) and nuclear marker (Ki67)). The results showed that $32 \%$ of tumors were luminal group A, $36 \%$ were from the luminal B group, 20\% were from the HER2 group and $12 \%$ of the tumors were from the basal-like group (Figure 2).

In our study, luminal A and luminal B groups were found to be the most common molecular subtypes in patients over 70 years of age (Figure 3 ).

By correlating the molecular type of tumors with the histological grade, in the majority of cases the histological grade (SBR) of luminal type $B$ and HER2 patients in our research was moderate grade (SBR II) (55.56\% and 60\% respectively), and

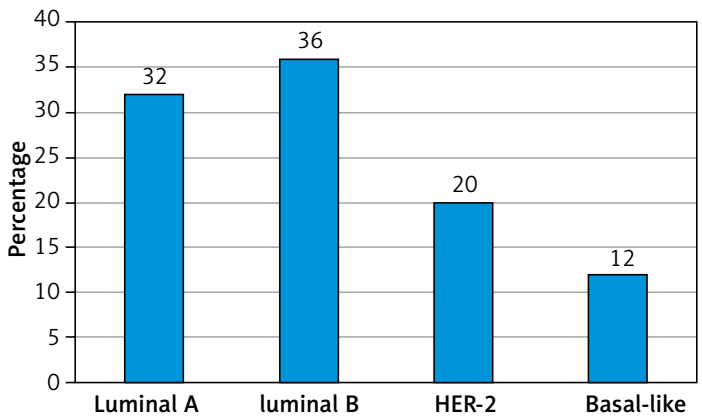

Figure 2. Graphical distribution of patients according to molecular subtypes
Table I. Characteristics of clinicopathological parameters of the study population

\begin{tabular}{|c|c|}
\hline Characteristics & Numbers of cases (\%) \\
\hline \multicolumn{2}{|l|}{ Tumor site: } \\
\hline Left breast & $18(36)$ \\
\hline Right breast & $18(36)$ \\
\hline \multicolumn{2}{|l|}{ SBR grade: } \\
\hline I & $0(0)$ \\
\hline II & $22(44)$ \\
\hline III & $28(56)$ \\
\hline \multicolumn{2}{|l|}{ Tumor size: } \\
\hline $\mathrm{T} 1$ & $14(28)$ \\
\hline $\mathrm{T} 2$ & $24(48)$ \\
\hline T3 & $4(8)$ \\
\hline T4 & $8(16)$ \\
\hline \multicolumn{2}{|c|}{ Lymph nodes status: } \\
\hline NO & $10(20)$ \\
\hline N1 & $24(48)$ \\
\hline N2 & $12(240$ \\
\hline N3 & $4(8)$ \\
\hline \multicolumn{2}{|c|}{ Metastatic status: } \\
\hline MO & $14(28)$ \\
\hline M1 & $2(4)$ \\
\hline$M x$ & $34(68)$ \\
\hline ER positive & $34(38)$ \\
\hline PR positive & $28(56)$ \\
\hline HER2 positive & $28(56)$ \\
\hline Ki67 (low) & $22(44)$ \\
\hline Ki67 (high) & $28(56)$ \\
\hline
\end{tabular}

the luminal A and basal-like subtypes had a high grade (SBR III) (62.5\% and 100\% respectively with $p=0.072$ ) (Table II).

The comparison of the average tumor sizes in our study population showed that there was a difference in tumor size in each molecular subtype such as: the HER2 subtype which had a tumor size of $77.5 \mathrm{~mm}$. Regarding the Basal-like subtype was tumor size of

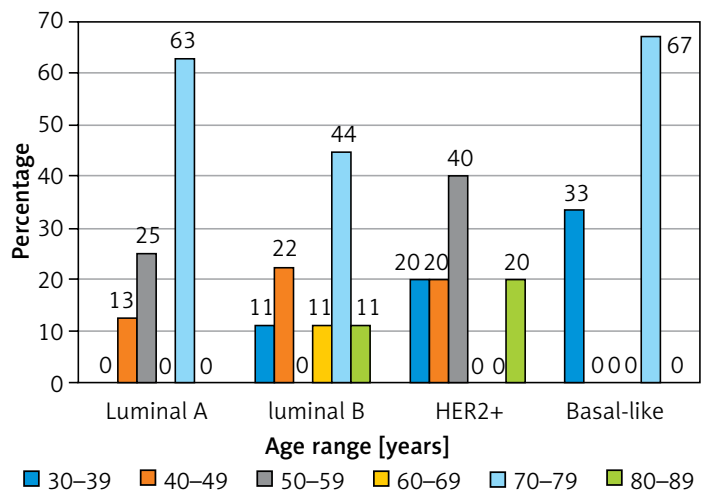

Figure 3. Graphical distribution of tumors by age according to molecular group 
$50 \mathrm{~mm}$. T2 size was predominant in the three molecular subtypes (HER2, luminal $B$ and luminal A, respectively $60 \%, 55.5 \%$ and $37.5 \%, p=0.013)$.

Basal and luminal $\mathrm{B}$ tumors had the highest nodal invasion rates of $100 \%$ and $89 \%$, respectively, followed by luminal A type of $88 \%$. For HER2 subtype tumors, the percentage corresponded to 60\% (Table II).

\section{Discussion}

Breast cancer is a major public health concern due to its increasing incidence. It is generally known that the risk of developing breast cancer increases with age.

The analysis of our results shows that the age group most affected is that between 70 and 79 years with a percentage of $44 \%$, unlike the Saudi study which showed that $54.3 \%$ of cases were in women under 50 [6]. This can be explained by the absence of a screening program for this age group in Algeria.

The SBR grade is a prognostic factor independent of tumor size and lymph node involvement, for which the Elston and Ellis grade is currently recommended in 2001. In our study population, SBR grade III tumors are the most frequent, with a percentage of $56 \%$ of cases. Our results are consistent with the study of Tahari et al. [7], as well as with the Indonesian study in 2019 which reported a percentage of $68.48 \%$ of cases with histological grade III and $29.09 \%$ with SBR grade $I I$ [8].

In the literature, size T2 was the majority in several studies, in particular Ries et al. [9], who noted $60 \%$ of cases of T2 status, which is consistent with our results, unlike the Moroccan study of Bouzid and his team [10].

The N1 lymph node status in our population is in the majority; these statistical values are consistent with the study by Tahari $Z$ and his team [7], who noted a high percentage of stage N1.

The presence of hormone receptors is a testament to the hormone dependence of breast cancer.

The IHC protein profile study revealed estrogen and progesterone receptor positivity in $68 \%$ and

Table II. Correlation of clinicopathological parameters with breast cancer subtypes

\begin{tabular}{|c|c|c|c|c|c|}
\hline Molecular subtypes & $\begin{array}{l}\text { Luminal A } \\
\begin{array}{c}N=16 \\
n=\%\end{array}\end{array}$ & $\begin{array}{l}\text { Luminal B } \\
\begin{array}{c}N=18 \\
n=\%\end{array}\end{array}$ & $\begin{array}{c}\text { HER2 neu } \\
\begin{array}{c}N=10 \\
n=\%\end{array}\end{array}$ & $\begin{array}{c}\text { Basal-like } \\
\begin{array}{c}N=6 \\
n=\%\end{array}\end{array}$ & $P$-value \\
\hline Mean age & 64.25 & 61.55 & 56.2 & 61 & \\
\hline Mean tumor size [mm] & 47.5 & 32.5 & 77.5 & 50 & \\
\hline Clinical stage of the tumor: & & & & & 0.013 \\
\hline T1 & $25 \%(4)$ & $33.33 \%(6)$ & $40 \%(4)$ & $0 \%(0)$ & \\
\hline $\mathrm{T} 2$ & $37.5 \%$ & $55.56 \%(10)$ & $60 \%(6)$ & $33.33 \%(2)$ & \\
\hline T3 & $0 \%(0)$ & $11.11 \%(2)$ & $0 \%(0)$ & $33.33 \%(2)$ & \\
\hline $\mathrm{T} 4$ & $37.5 \%(6)$ & $0 \%(0)$ & $05(0)$ & $33.33 \%(2)$ & \\
\hline Lymph nodes status: & & & & & 0.117 \\
\hline Positive (+) & $87.5 \%(14)$ & $88.89 \%(16)$ & $60 \%(6)$ & $100 \%(6)$ & \\
\hline Negative (-) & $12.5 \%(2)$ & $11.11 \%(2)$ & $40 \%(4)$ & $0 \%(0)$ & \\
\hline Metastatic status: & & & & & 0.219 \\
\hline Positive (+) & $12.5 \%(2)$ & $0 \% 90)$ & $0 \%(0)$ & $0 \%(0)$ & \\
\hline Negative (-) & $87.5 \%(14)$ & $100 \%(18)$ & $100 \%(10)$ & $100 \%(6)$ & \\
\hline SBR grad: & & & & & 0.072 \\
\hline 1 & $0 \%(0)$ & $0 \%(0)$ & $0 \%(0)$ & $0 \%(0)$ & \\
\hline II & $37.5 \%(6)$ & $55.56 \%(10)$ & $60 \%(6)$ & $0 \%(0)$ & \\
\hline III & $62.5 \%(10)$ & $44.44 \%(8)$ & $40 \%(4)$ & $100 \%(6)$ & \\
\hline \multicolumn{6}{|l|}{ Estrogen receptors: } \\
\hline Positive $(+)$ & $100 \%(16)$ & $100 \%(16)$ & $0 \%(0)$ & $0 \%(0)$ & \\
\hline Negative $(-)$ & $0 \%(0)$ & $0 \%(0)$ & $100 \%(10)$ & $100 \%(6)$ & \\
\hline \multicolumn{6}{|l|}{ Progesteron receptors: } \\
\hline Positive $(+)$ & $72 \%(12)$ & $78 \%(14)$ & $0 \%(0)$ & $0 \%(0)$ & \\
\hline Negative (-) & $25 \%(4)$ & $22 \%(4)$ & $100 \%(10)$ & $100 \%(6)$ & \\
\hline \multicolumn{6}{|l|}{ HER2: } \\
\hline Positive $(+)$ & $12.5 \%(2)$ & $88.8 \%(16)$ & $100 \%(10)$ & $0 \%(0)$ & \\
\hline Negative (-) & $87.5 \%(14)$ & $11.2 \%(2)$ & $0 \% 900$ & $100 \%(6)$ & \\
\hline
\end{tabular}


$56 \%$, respectively. These results are of the same order as among the French $(68 \%$ RE +$)$ [11].

We also found $56 \%$ of cases that expressed progesterone receptors; these results are consistent with Ayadi's [12] study which found $70 \%$ of positive progesterone.

Our percentage of HER2 profile positivity correlates with several recently published studies, such as the Indonesian study of Swandari [8], which notes $57.61 \%$ positivity.

Our Ki67 biomarker results are lower than those obtained in the literature, in particular the Indonesian study [8] with a percentage of Ki67 $>14$ which exceeds $83 \%$ of the total.

This study noted a predominance of the luminal B molecular subtype (36\%). The result is similar to other studies established in regions of Southeast Asia (luminal B subtype 56.5\%) [13].

Our results showed a majority incidence rate of the luminal A molecular subtype in our patients aged $\geq 70$ years, the percentage of which was around $63 \%$. Compared to the literature, our results agree with the Indian study established in 2019 [14], showed that the incidence rate of luminal A subtype was high in patients aged $\geq 70$ years with a percentage of $72 \%$.

The predominant histological grade of luminal $B$ and HER2 type patients in this research was moderate grade (SBR II), and for luminal $A$ and basal types it was high grade (SBR III), unlike Swandari's study [8], in which the patients with a luminal $B$ and HER2 profile mainly present the SBR III grade, with a percentage of $66.7 \%$ and $80.6 \%$ respectively.

In our series, the HER2 subtype presents the largest tumor size $(77.5 \mathrm{~mm})$, followed by the basal-like type, with an average tumor size of $50 \mathrm{~mm}$. Contrary to what has been found in the literature, notably the Saudi study published in 2019 which noted that the majority of tumor sizes (of the HER2 and basal-like subtypes) varied between 20 and $50 \mathrm{~mm}$ [6]. This can be explained by the difference in therapeutic management between countries or by the delay in diagnosis in Algeria.

Data obtained in our research indicate that luminal group B tumors would appear to have a worse prognosis and a very high potential for malignancy.

In conclusion, our knowledge of the heterogeneity of breast cancer at the histological, phenotypical and molecular level has been enriched thanks to the immunohistochemical analyses which have made it possible to approach the molecular classification by means of the genetic signatures described by Peru and his collaborators. The determination of molecular groups is therefore crucial for a better therapeutic strategy.

In our present study, the most frequent molecular phenotype is luminal B (36\%) followed by lu- minal A (32\%), HER2 (20\%) and finally basal-like $(12 \%)$.

The results obtained, in which tumors of the HER2 and basal-like phenotype were associated with clinical and histopathological characteristics which are more aggressive than tumors of the luminal phenotype, are encouraging.

\section{Acknowledgments}

The authors wish to thank Mr Azziz Mohamed Bensnouci, Laboratory of Anatomopathology of the Regional Military University Hospital of Oran (HMRUO), and Mrs Samia Khalifa, Laboratory of Anatomy and Pathological Cytology, University Hospital Establishment, November 1, 1954, Oran.

The study was carried out at the Pathology Laboratory of the Oran Regional University Military Hospital (HMRUO) and the Laboratory of Anatomy and Pathological Cytology, University Hospital Establishment, November 1, 1954, Oran.

\section{Conflict of interest}

The authors declare no conflict of interest.

\section{References}

1. Nuket E, Evrim Y, Baha Z.Classification moléculaire du cancer du sein: du traditionnel, à l'ancienne à un nouvel âge, et une nouvelle façon. Eur J Breast Health 2015; 5: 59-66.

2. Sobin LH, Gospodarowicz MK, Wittekind C. TNM Classification of Malignant Tumours. Willey 2010.

3. Cabarrot E. Histoire naturelle des cancers du sein. Encyclopédie Médicochirurgicale. Gynécologie OMS 2000; 865-A-10.

4. Séradour B. Rapport des anatomopathologistes du groupe de travail. dépistage du cancer du sein» de l'union européenne 1996; 315-33.

5. Bloom H, Richardson W. Histological grading and prognosis in breast cancer; a study of 1409 cases of which 359 have been followed for 15 years. Br J Cancer 1957; 11: 359-77.

6. Al-thoubaity FK. Molecular classification of breast cancer: a retrospective cohort study. Ann Med Surg 2019; 49: 44-8.

7. Tahari Z, Medjdoub A, Sahraoui T, El Kebir FZ. Étude histopathologique des cancers mammaires dans l'ouest algérien: à propos de 81 cas Histopathological study of breast cancers in west Algeria: 81 cases reports. J Afr Cancer 2009; 1: 196-9.

8. Swandari P, Raharjo EN, Niasari M, Azizah F. Luminal B is the most common intrinsic molecular subtypes of breast carcinoma. A P J Cancer Prev 2019; 20: 2247-52.

9. Ries LA, Melbert D, Krapcho M, Stinchcomb DG, Howlader N, Horner MJ. National Caner Institute Bethesda, SEER Cancer Statistics Review 2008; 1975-2005.

10. Bouzid N, Diakit K, Elomrani A, Khouchani M. Cancer Du Sein Chez La Femme Âgée: Experience Du Service D'oncoradiothérapie Chu De Marrakech. J Homepage 2018; 6: 834-42.

11. Vincent-Salomon A, MacGrogan G, Couturier J, Arnould L, Denoux Y, Fiche M. Calibration of immunohistochemistry for assessment of HER2 in breast cancer: results of 
the french multicentre GEFPICS study. Histopathology 2003; 42: 337-47.

12. AyadiL,HYPERLINK«https://www.ncbi.nlm.nih.gov/pubmed/ ?term $=$ Khabir\%20A\%5BAuthor\%5D\&cauthor=true\&cauthor uid=18945339» Khabir A, HYPERLINK «https:// www.ncbi.nlm.nih.gov/pubmed/?term=Amouri\%20H\%5BAuthor\%5D\&cauthor=true\&cauthor uid=18945339» Amouri $\mathrm{H}$, et al. Correlation of HER- $\overline{2}$ overexpression with clinico-pathological parameters in Tunisian breast carcinoma. World J Surg Oncol 2008; 6: 112.

13. Thang V, Skoog L, Duc NB, Van TT, Tani E, Thang V. Cell proliferation measured by Ki67 staining and correlation to clinicopathological parameters in operable breast carcinomas from Vietnamese and Swedish patients. J Anal Oncol 2015; 4: 58-68

14. Pandit P, Patil R, Palwe V, Gandhe S, Patil R, Nagarkar R. Prevalence of molecular subtypes of breast cancer: a single institutional experience of 2062 patients. Eur J Breast Health 2020; 16: 39-43. 